\title{
Chemotherapy oxaliplatin sensitizes prostate cancer to immune checkpoint blockade therapies via stimulating tumor immunogenicity
}

\author{
JIN ZHOU* ${ }^{*}$, TUO YANG ${ }^{*}$, LIPENG LIU and BINGXIN LU \\ Department of Urology, Nankai Hospital, Tianjin 300100, P.R. China
}

Received November 11, 2016; Accepted May 26, 2017

DOI: $10.3892 / \mathrm{mmr} .2017 .6908$

\begin{abstract}
Even though standard treatment options are available for prostate cancer patients, prostate cancer is still a leading cause of death in many Western countries due to drug resistance and recurrence. Immune checkpoint blockade therapy has been proved to be very effective in some melanoma patients, which might dependent on the preconditioned immune system. Here we explored the effect of chemotherapy (oxaliplatin) in combination with immune checkpoint blockade therapy (anti-PD-1 treatment) in prostate cancer cell lines and pre-clinical animal models. We found that oxaliplatin is effective in castration-resistant cells and enhanced the response of prostate cancer to anti-PD-1 antibody treatment. Oxaliplatin stimulated the immunogenic potential and established a pro-immune microenvironment in prostate cancer. In conclusion, oxaliplatin sensitized anti-PD-1 treatment in prostate cancer and this combination may be an option for castration-resistant prostate cancer patients.
\end{abstract}

\section{Introduction}

Prostate cancer is the most common diagnosed male cancer in western countries (1) and big variation of the prostate cancer incidence exists among different populations $(2,3)$. Although prostate cancer has relatively low mortality compared with other cancers, its high incidence makes prostate cancer the second leading cause of cancer-related death in USA $(3,4)$. Patients have multiple active treatment options for prostate cancer, such as radical prostatectomy, radiotherapy, vaccine

Correspondence to: Dr Bingxin Lu, Department of Urology, Nankai Hospital, 122 Sanwei Road, Nankai, Tianjin 300100, P.R. China

E-mail: lubingxin575@163.com

*Contributed equally

Abbreviation: ADT, androgen deprivation therapy

Key words: prostate cancer, drug resistance, immune checkpoint blockade, chemotherapy, adaptive immunity treatment and androgen deprivation therapy (ADT) $(3,5)$. Using these methods, sound effects have been achieved in early stage prostate cancer, showing apparently extended survival time. However, for late stage or metastatic prostate cancer, ADT drug resistance and recurrence often occur. In these cases, chemotherapy becomes a common option (6). However, more clinical interventions are required due to moderate efficacy of chemotherapies.

Immunotherapy for cancers obtained increased attention due to the knowledge that tumor cells can be control by immune response and positive effects that were observed in some cancers (7). It has been widely accepted that activated host cytotoxic $\mathrm{CD}^{+} \mathrm{T}$ cells can eliminate tumor cells once infiltrate into tumor tissue. Consistently, $\mathrm{CD}^{+}$tumor-infiltrating lymphocytes and a high CD8+/regulatory $\mathrm{T}$ (Treg) cell ratio are associated with positive prognosis in cancers, such as ovarian cancer (8), andcolorectal cancer (9), while CD8 ${ }^{+}$ $\mathrm{T}$ cell impairment and increase of Treg cells are associated with poor prognosis of cancer patients (10). However, in tumor tissue, effective $\mathrm{T}$ cell immune response is usually absent while abnormally increased activity of inhibitory immune checkpoint signaling pathways are widely observed. Increased expression of programmed death-1 (PD-1)/PD-ligand 1 (PD-L1) and PD-L2 axisand cytotoxic lymphocyte antigen (CTLA-4)/CD28 system depressed CD8 ${ }^{+} \mathrm{T}$ cell activity in tumor microenvironment (7). Thus, refining $\mathrm{T}$ cell immune response in tumor microenvironment could be a potential way of prostate cancer treatment.

Several drugs targeting the $\mathrm{T}$ cell inhibitory checkpoint signaling pathways have been used in clinic application and promising effects have been observed. Pembrolizumab and ipilimumab, the respective antibodies targeting PD-1 and CTLA-4, have been approved by the US Food and Drug Administration for treating advanced melanoma patients $(7,11,12)$. Around $20 \%$ of advanced melanoma patients got extended survival time of at least 3 years after ipilimumab treatment (13). What's more, combination of conventional chemotherapies were considered as a synergistic approach of immune checkpoint blockades (14-16). However, whether immune checkpoint blockades can benefit prostate cancer patients is still unclear. Here, we aimed to evaluate the therapeutic values of immune checkpoint blockades and potential synergistic effects of chemotherapy immune checkpoint blockade in pre-clinical prostate cancer models. 


\section{Materials and methods}

Cell culture. We purchased mouse prostate cancer cell lines, PTEN-CaP8 and PNEC30, and human prostate cancer cell lines, DU145 and PC3 from ATCC. PTEN-CaP8 cells were cultured using DMEM medium supplemented with $10 \%$ fetal bovine serum (FBS; Sigma-Aldrich, St. Louis, MO, USA), $100 \mathrm{U} / \mathrm{ml}$ of penicillin and $100 \mu \mathrm{g} / \mathrm{ml}$ of streptomycin, $25 \mu \mathrm{g} / \mathrm{ml}$ bovine pituitary extract (BPE), $5 \mu \mathrm{g} / \mathrm{ml}$ bovine insulin and $6 \mathrm{ng} / \mathrm{ml}$ recombinant epidermal growth factor (Thermo Fisher Scientific, Inc., Waltham, MA, USA). PNEC30 cells were cultured using Neural Progenitor Basal Medium (NPBM) supplemented with 10\% FBS, $100 \mathrm{U} / \mathrm{ml}$ of penicillin and $100 \mu \mathrm{g} / \mathrm{ml}$ of streptomycin, $0.3 \% \mathrm{BPE}$, and additives that are supplied with the NPMM Bullet Kit (Lonza, Verviers, Belgium). DU145 and PC3 cells were cultured by DMEM medium supplemented with 10\% FBS and $100 \mathrm{U} / \mathrm{ml}$ of penicillin and $100 \mu \mathrm{g} / \mathrm{ml}$ of streptomycin. When the cells grew to $85 \%$ confluent, they were sub-cultured.

Patient samples. A total number of 100 prostate patients who got surgery treatment during January 2001 to December 2004 in Tianjin Nankai Hospital were included in our study. We collected the formalin-fixed, paraffin-embedded (FFPE) tumor tissues ofall cases with informed consents assigned by each patient. All patients didn't take any radiotherapy or chemotherapy before surgery. This study was approved by the ethics committee of Tianjin Nankai Hospital. Clinicopathological characteristics of these samples were summarized in Table I. AJCC cancer staging manual 7 th edition was used as the criteria for TNM classification. Gleason gradewas used to evaluate the differentiation of tumor tissues. Follow-up of these patients started from the date of surgery and ended at December 2014 and overall survival was the interval between the date of death and the date of surgery. Patients died due to other reasons than prostate cancer were excluded from this study.

Immunohistochemistry. Immunohistochemistry (IHC) was performed to evaluate the expression of CD8 in the tumor tissue of prostate cancer patients. All the procedures followed the standard IHC procedures. Briefly, FFPE tissue samples were deparaffinized within xylene and rehydrated in gradient ethanol. Then tissue samples wereincubated in 1X Reveal Decloaker (Biocare Medical, LLC., Concord, CA, US) at $120^{\circ} \mathrm{C}$ for $45 \mathrm{~min}$ for antigen retrieval and reducing non-specific background staining. After washing the slides with PBST, 3\% hydrogen peroxide was added for incubation in dark to quench the endogenous peroxidase within the cells. Then, washed the slides again for 3 times using PBST and block them at room temperature for 15 minusing $5 \%$ bovine serum albumin. Subsequently, mouse monoclonal anti-human CD8 antibody (1:100; Santa Cruz Biotechnology Inc., Santa Cruz, CA, USA) was added for incubation overnight at $4^{\circ} \mathrm{C}$. Then horseradish peroxidase (HRP) linked secondary antibody (1:1,000; Abcam, Cambridge, UK) was added for incubation at room temperature for $1 \mathrm{~h}$. Staining was completed by incubation with DAB for $5 \mathrm{~min}$. Then sample slides were mounted immediately and detected under light microscope. Five fields of each slide were selected for observation, and the final score was determined based on the average number (AN) of positive
Table I. Relationship between the number of $\mathrm{CD}^{+} \mathrm{T}$ cells and clinicopathological features of prostate cancer.

\begin{tabular}{|c|c|c|c|}
\hline \multirow[b]{2}{*}{ Features } & \multicolumn{2}{|c|}{$\mathrm{CD}^{+} \mathrm{T}$ cells } & \multirow[b]{2}{*}{ P-value } \\
\hline & Low $(\leq 7)(\%)$ & $\operatorname{High}(>7)(\%)$ & \\
\hline Age & & & 0.542 \\
\hline$<65$ & $33(62.3)$ & $20(37.7)$ & \\
\hline$\geq 65$ & $32(68.1)$ & $15(31.9)$ & \\
\hline Gleason scoring & & & 0.723 \\
\hline$<6$ & $50(64.1)$ & $28(35.9)$ & \\
\hline$\geq 6$ & $15(68.2)$ & $7(31.8)$ & \\
\hline T Stage & & & 0.304 \\
\hline $\mathrm{T} 1+\mathrm{T} 2$ & $8(53.3)$ & $7(46.7)$ & \\
\hline $\mathrm{T} 3+\mathrm{T} 4$ & $57(67.1)$ & $28(32.9)$ & \\
\hline Lymph node & & & 0.402 \\
\hline N0-N2 & $43(62.3)$ & $26(37.7)$ & \\
\hline N3-N4 & $22(71.0)$ & $9(29.0)$ & \\
\hline Metastasis & & & 0.295 \\
\hline Negative & $63(64.3)$ & $35(35.7)$ & \\
\hline Positive & $2(100.0)$ & $0(0.0)$ & \\
\hline TNM stage & & & 0.013 \\
\hline $\mathrm{I}+\mathrm{II}$ & $24(52.2)$ & $22(47.8)$ & \\
\hline III+IV & $41(75.9)$ & $13(24.1)$ & \\
\hline Survival status & & & 0.002 \\
\hline Alive & $25(50.0)$ & $25(50.0)$ & \\
\hline Dead & $40(80.0)$ & $10(20)$ & \\
\hline
\end{tabular}

cells in each field: High expression if $\mathrm{AN}>7$, low expression if $\mathrm{AN} \leq 7$.

Cytokine assay. We detected the expression of cytokines (IFN- $\gamma$, PD-L1, IL-2, CXCL-12, TGF- $\beta$ and IL-10) in xenograft mouse prostate tumor tissue using cytokine-specificbead-based assay (BioLegend, Inc., London, UK). Prostate tumor tissue from xenograft mouse model treated with different drugs (saline, oxaliplatin, anti-PD-1 antibody (Ab), or the combination of Oxaliplatinand anti-PD-1 Ab) were cut, minced and filtered for cell precipitation. Then, protein extraction of these cell precipitations was performed using RIPA buffer under the presence of protein inhibitor. Protein concentration was measured using BCA protein assay followed by protein concentration normalization. The subsequent processes of bead-based assays were performed following the manufacturer's instruction. Triple measurements were conducted for each sample and the mean values were used for final analysis.

Fluorescence-activated cell sorter (FACS) analysis. FACS analysis was used to measure the number of $\mathrm{CD}^{+} \mathrm{T}$ cells $\left(\mathrm{CD}^{+}, \mathrm{CD}^{-}, \mathrm{CD}^{+}\right)$, Treg cells $\left(\mathrm{CD}^{+}, \mathrm{CD}^{+}, \mathrm{CD}^{-}\right.$and $\left.\mathrm{CD} 25^{+}\right)$and expression of calreticulin (CRT) and staining of DAPI. All of the fluorescence conjugated primary antibodies were purchased from BioLegend, Inc. and Abcam. After harvested, the cells were incubated with primary antibodies for $20 \mathrm{~min}$ at $4^{\circ} \mathrm{C}$. After washed with PBS for three times, the 
A DU145 cell line

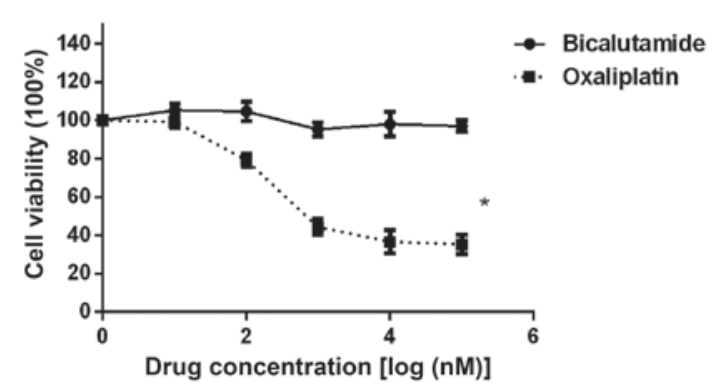

B

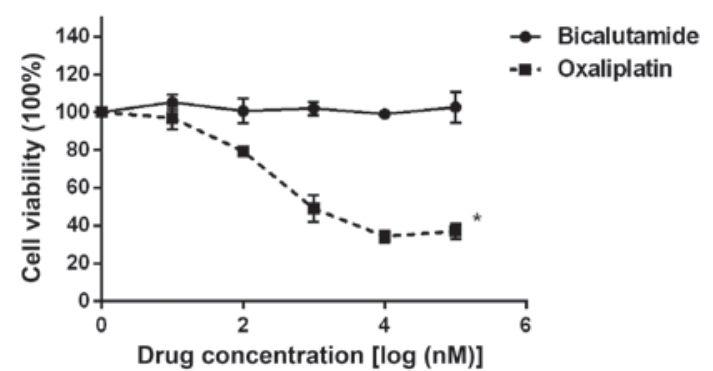

C

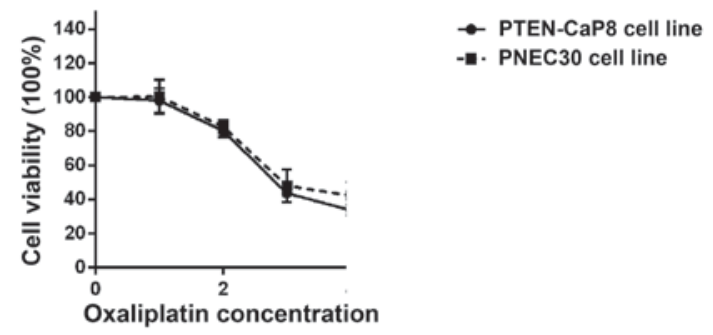

D

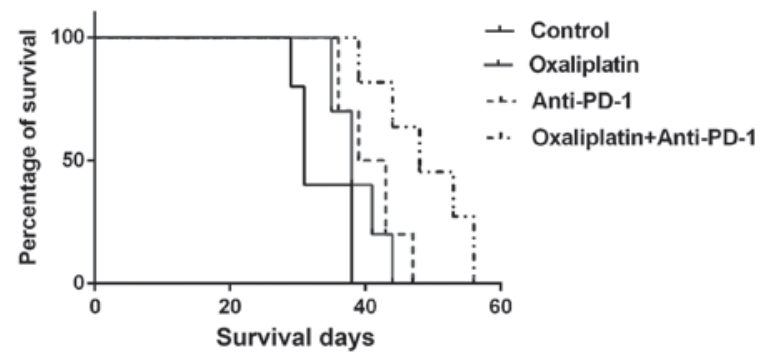

Figure 1. Chemotherapy can inhibit the growth of castration-resistant prostate cancer cells. (A and B) Cell viability analysis of human prostate cancer cell line DU145 and PC3 treated with gradient concentrations of Bicalutamide and Oxa; (C) Cell viability analysis of mouse prostate cancer cell lines PTEN-CaP8 and PNEC30 treated with gradients concentrations of Oxa. (D) Survival analysis of prostate cancer xenograft mice treated with Oxa and/or Anti-PD-1 Ab *significant statistical difference was detected.

stained cells were analyzed on BDFACSCanto II equipment (BD Biosciences, San Diego, CA, USA). Data visualization was performed using FlowJo software.

Xenograft mouse model. A subcutaneous prostate cancer model was established using five-week-old female NOD/SCID nude mice (18-20 g; Shanghai SLAC Laboratory Animal Co., Ltd.) with PNEC30 to analyze the in vivo activity of different treatments. All mice were kept under specific pathogen-free environment with a 12-h light-dark cycle, standard food, and free access to autoclaved water. A total of $5 \times 10^{6}$ PNEC 30 cells were inoculated subcutaneously to flanks of the mice. All treatments started one week later of tumor seeding. Oxaliplatin (Oxa) and anti-PD-1 antibody were injected intraperitoneally once a week for 3 weeks ( 2.5 and $3 \mathrm{mg} / \mathrm{kg}$, respectively). Tumor size and body weight were measured weekly. Tumor volume was calculated according to the following formula: tumor volume $=$ length $\mathrm{x}$ width $2 \mathrm{x} \mathrm{p} / 6$. Development of more than $20 \%$ body weight loose, serious ulceration and any other symptoms of distress were considered as death.

Cell viability. Cell viability assay was performed using Cell Counting kit 8 (CCK-8; Sigma-Aldrich). A total number of $1.0 \times 10^{4}$ cells were seeded in each well of 96-well plate. The cells of different groups were culture with $100 \mu 1$ appropriate medium accordingly for $24 \mathrm{~h}$, followed by different treatments for $24 \mathrm{~h}$. Then, $10 \mu \mathrm{l}$ of CCK- 8 solution was added to each plate for incubation of $1 \mathrm{~h}$. At last, the absorbance at $450 \mathrm{~nm}$ was measured by MRX II microplate reader (Dynex Technologies, West Sussex, UK). The final results were calculated by normalizing each OD value to that of the control group.
Enzyme-linked immunosorbent assay. Enzyme-linked immunosorbent assay (ELISA) was performed to measure the expression of high mobility group box 1 (HMGB1) protein in prostate cancer cell lines PETN-Cap8 and PNEC30 using ELISA kit (R\&D Systems, Inc., Minneapolis, MN, USA). Every procedure was performed following the manufacturer's instruction. The total protein normalization is based on the BCA assay. Two people read one case blindly without knowing the clinic data.

Statistical analysis. GraphPad Prism software (GraphPad Software, Inc., La Jolla, CA, USA) and SPSS 17.0 software (SPSS, Inc., Chicago, IL, USA) were used for statistical analysis and data visualization. Statistical difference of comparisons was analyzed by t-test, Chi-square test, or one-way ANOVA appropriately according to the data characteristics. Bonferroni's pairwise comparison was used to analyze the difference between different treatments. Kaplan-Meier method and log-rank test were used for survival analysis and evaluating the difference between different cohorts, respectively. Multivariate Cox regression model was used for determine the independent predictors of survival of prostate cancer patients. The detail is as reported before (17). A two-tailed $\mathrm{P}<0.05$ was considered to indicate a statistically significant difference.

\section{Results}

Oxaliplatin sensitizes the prostate cancer cells to immune checkpoint blockade therapy. ADT therapy is a classic therapy for prostate cancer, but some patients got resistance to it. Chemotherapy is often chosen to treat these patients with 
Table II. Multivariate COX regression model analysis of the overall survival of prostate cancer patients.

\begin{tabular}{lcc}
\hline Factors & P-value & HR (95\% CI) \\
\hline Age ( $\geq 65$ vs. <65) & 0.530 & $1.204(0.675-2.149)$ \\
Gleason scoring ( $\geq 6$ vs. $<6)$ & 0.002 & $2.548(1.424-4.560)$ \\
TNM stage (III-IV vs. I-II) & 0.001 & $3.231(1.622-6.437)$ \\
T stage (T3-T4 vs. T1-T2) & 0.915 & $1.051(0.422-2.618)$ \\
Lymph node (N3-N4 vs. N0-N2) & 0.594 & $1.181(0.640-2.180)$ \\
Metastasis (Yes vs. No) & 0.247 & $2.484(0.532-11.604)$ \\
CD8+ T cells (High vs. Low) & 0.047 & $0.482(0.235-0.991)$ \\
\hline
\end{tabular}
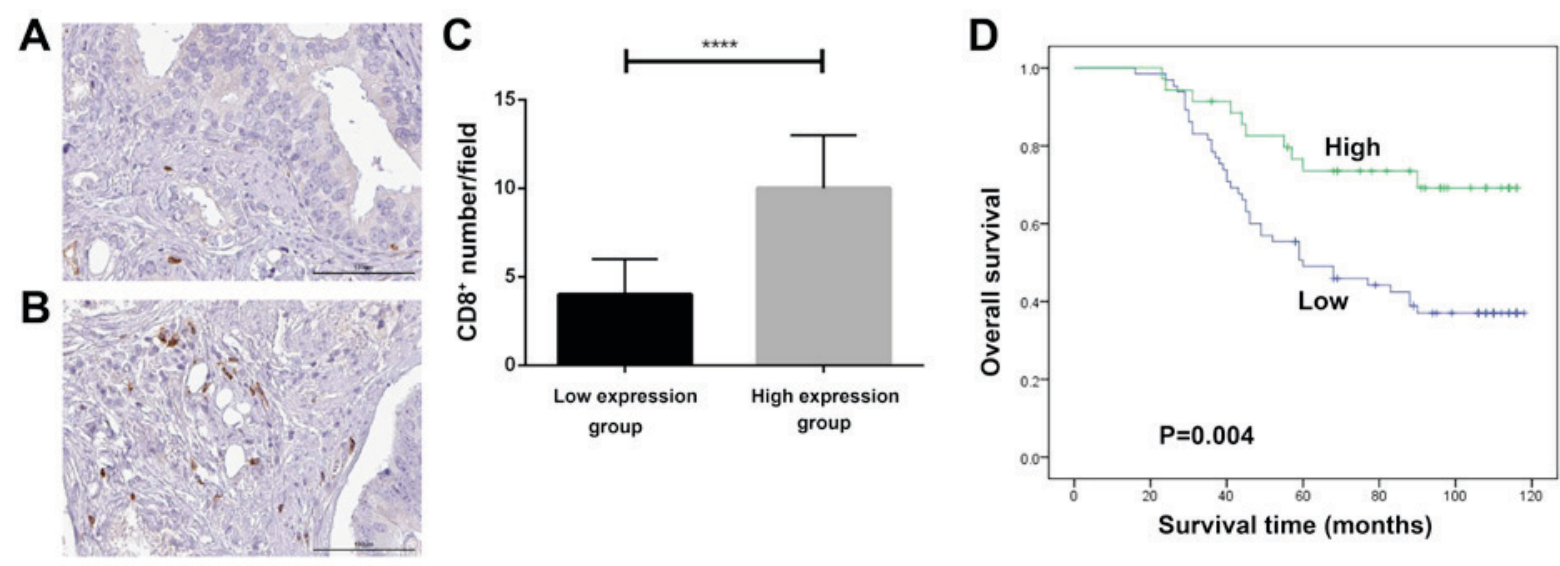

Figure 2. Prostate cancer patients with high $\mathrm{CD} 8^{+} \mathrm{T}$ cells in tumor stroma tended to have better survival. (A and B) Representative pictures showing IHC staining of low CD8 expression and high CD8 expression, respectively. (C) Average number of CD8 ${ }^{+} \mathrm{T}$ cells of prostate cancer patients of low CD8 expression group and high CD8 expression group. (D) Survival analysis of prostate cancer patients based on the expression level of CD8 in tumor stroma. Patients with high CD8 expression tend to have better survival than those with low CD8 expression.

high ADT resistance. Here we treated two human prostate cancer cell lines DU145 and PC3 with bicalutamide andoxaliplatin. As shown in Fig. 1A and B, these two human prostate cancer cell lines were highly resistant to Bicalutamide, but sensitive to oxaliplatin treatment. This indicates that chemotherapy might be a choice for the castration-resistant prostate cancer patients. Then we also confirmed the effect of oxaliplatinin two murine prostate cancer cell lines PTEN-Cap8 and PNEC30 (Fig. 1C). In prostate cancer xenograft mouse model, we used oxaliplatin treatment in combination with anti-PD-1 Ab. Interestingly, the mice treated by oxaliplatin plus anti-PDAb got the best survival compared with the mice accepted Oxa or anti-PD Ab single treatment (Fig. 1D), suggesting that the chemotherapy might sensitize the prostate cancer to anti-PD-1 treatment.

High expression of CD8 is an independent predictor of good prognosis of prostate cancer patients. The data shown in Fig. 1 suggested that immune checkpoint blockade therapy is effective in prostate cancer especially in combination with oxaliplatin. $\mathrm{CD} 8^{+} \mathrm{T}$ cells are the basis of immune checkpoint blockade therapies. For this reason, we collected 100 prostate cancer patient tissue samples and evaluated the clinical significance of $\mathrm{CD}^{+} \mathrm{T}$ cells in prostate cancer. All the clinic pathological features of these patients and their relationship to the $\mathrm{CD} 8^{+} \mathrm{T}$ cells number were summarized in Table I. Patients with higher $\mathrm{CD}^{+} \mathrm{T}$ cells number have lower proportion of advanced TNF stages (III+IV) $(\mathrm{P}=0.013)$. Importantly, patients with higher $\mathrm{CD} 8^{+} \mathrm{T}$ cells number have better survivalrate $(\mathrm{P}=0.002)$. Furthermore, as shown in Fig. 2D, the survival analysis indicated that patients with high $\mathrm{CD}^{+} \mathrm{T}$ cells number had longer survival than those with low number $(\mathrm{P}=0.004)$. Consistently, Cox regression model analysis proved that high $\mathrm{CD}^{+} \mathrm{T}$ cells number is an independent favorable predictor of prostate cancer patients $(\mathrm{P}=0.047, \mathrm{HR}=0.482$, 95\% CI: 0.235-0.991), while high Gleason score and high TNM stage are adverse independent predictor of these patients with $\mathrm{P}=0.002$ ( $\mathrm{HR}=2.548,95 \% \mathrm{CI}$ : 1.424-4.560) and 0.001 (HR=3.231, 95\% CI: 1.622-6.437), respectively (Table II).

Oxaliplatin induces immunogenic phenotype in prostate cancer cells. Based on the evidence mentioned above, it is highly likely that immune response was activated by the combination of oxaliplatinand anti-PD-1 therapy. Thus, we tested the exposure of two the immunogenic makers in prostate cancer cell lines PTEN-CaP8 and PNEC30 treated by oxaliplatin: HMGB1 and calreticulin (CRT). As shown in Fig. 3, after oxaliplatin treatment for $24 \mathrm{~h}$, the exposure of both HMGB1 and CRT were increased significantly. This suggested that oxaliplatin could activate the immunogenic phenotype of prostate cancer cells. 
A

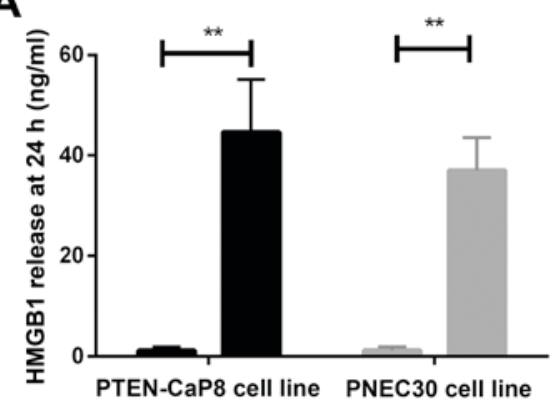

B

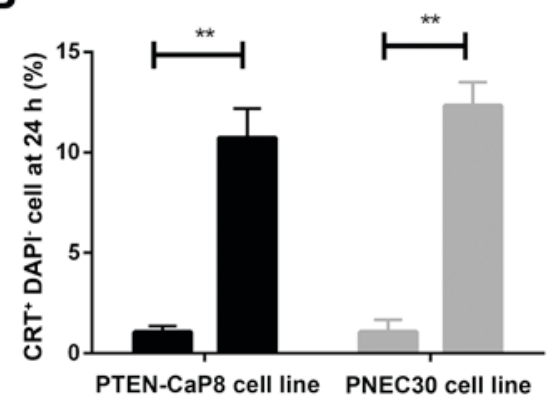

Figure 3. Chemotherapy induced immunogenic phenotype in prostate cancer cell lines. (A) Quantitative analysis of HMGB1 released in mouse prostate cancer cell lines PTEN-CaP8 and PNEC30 treated with Oxa for $24 \mathrm{~h}$ in vitro. HMGB1 release was highly increased after Oxa treatment. (B) Quantity of CRT exposed by PTEN-CaP8 and PNEC30 cell lines was significantly increased after Oxa treatment for $24 \mathrm{~h}$ in vitro.

A

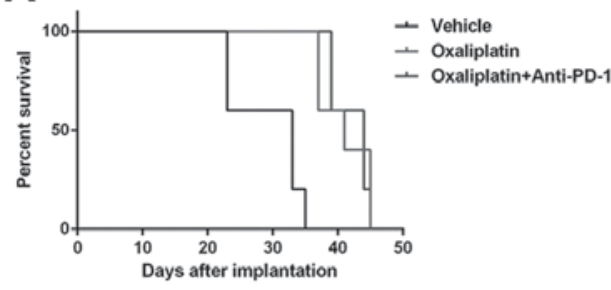

P-values of each comparison Oxaliplatin vs. vehicle: $\mathbf{0 . 0 0 0 2}$ Oxaliplatin vs.

Oxaliplatin+Anti-PD-1: NS

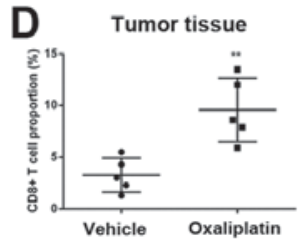

B
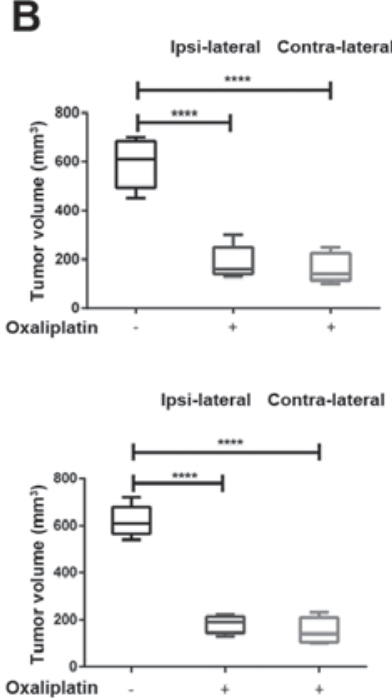

C

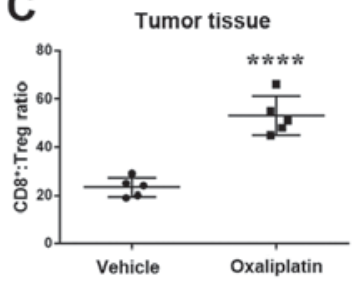

Spleen

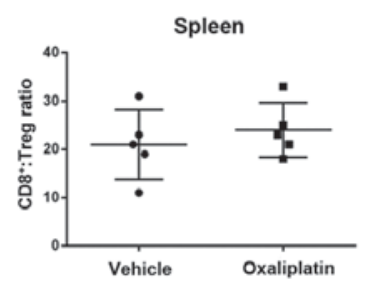

Lymph node

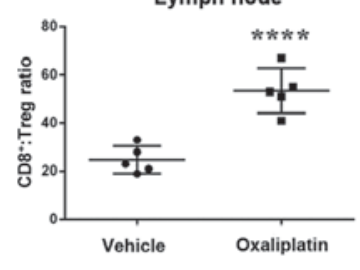

Bone marrow

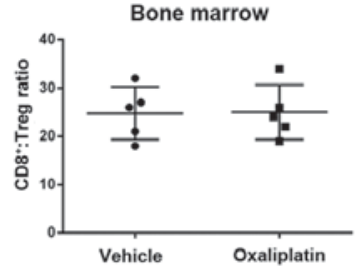

Figure 4. Chemotherapy inhibited prostate cancer growth though inducing immune response. (A) Survival analysis of NOD-SCID mice bearing prostate cancer treated with Oxa with/without anti-PD-1 Ab. Oxa treatment has extended the survival of these prostate cancer xenograft mouse models, but the addition of anti-PD-1 treatment didn't make significant difference regarding the survival of these mice. (B) Tumor growth of xenograft prostate cancer in Balb/c mice vaccinated with Oxa-killed prostate cancer cells. (C) The ratio of $\mathrm{CD}^{+} \mathrm{T}$ cell and Treg cells at different sites of immune cells recruitment from bone marrow to tumor tissue. (D) Change of $\mathrm{CD}^{+}$and $\mathrm{CD} 4^{+} \mathrm{T}$ cells in tumor tissue after Oxa treatment.

Oxaliplatin sensitizes prostate cancer cell to immune checkpoint blockade through inducing systemic immune response. To further explore the mechanisms by which oxaliplatin sensitizes prostate cancer cell to immune checkpoint blockade, we established prostate cancer xenograft mouse model using NOD-SCID mice, wide type Balb/c mice andPNEC30 cell lines. Fig. 4A showed the survival analysis of NOD-SCID bearing xenograft prostate cancer treated by oxaliplatin and/or anti-PD-1 therapy. Interestingly, even though the survival time of both oxaliplatin and oxaliplatin + anti-PD-1 $\mathrm{Ab}$ treated groups has been extended vs. PBS control, there is no difference between these two treatments. This suggested that the anti-PD-1 Ab synergistic effects of oxaliplatin rely on complete adaptive immune system. We further measured the growth of xenograft prostate cancer in wild type Balb/c mice which were vaccinated by oxaliplatin-killed prostate cancer cells. As shown in Fig. 4B, in wild type Balb/c mice, the tumor in control groups grew much quicker than that of oxaliplatin treated group. This indicated that oxaliplatin-killed prostate cancer cells vaccination can induce tumor growth inhibition. What's more, as both ipsilateral and contralateral tumor growth were inhibited by oxaliplatin treatment, it was proposed that not local immune response but systemic response caused by vaccination induced the antitumor effect. Mechanistically, we found that oxaliplatin treatment altered the ratio of $\mathrm{CD}^{+} \mathrm{T}$ cells to Treg cells in tumor tissue and tumor draining lymph nodes (Fig. 4C). Further, the Oxaliplatin treatment increased $\mathrm{CD}^{+} \mathrm{T}$ cell infiltration in the tumor tissue but not $\mathrm{CD}^{+} \mathrm{T}$ cells (Fig. 4D). Taken together, oxaliplatin sensitizes anti-PD-1 Ab treatment through activating systemic tumor immune response.

Combination of oxaliplatin and anti-PD-1 Ab changes the cytokine expression in prostate cancer. Immune response is regulated by cytokine network. Thus, we measured the expression of some key regulatory cytokines (IFN- $\gamma$, PD-L1, IL-2, CXCL-12, TGF- $\beta$, and IL-10) in the tumor tissue of xenograft mouse model. As shown in Fig. 5, 


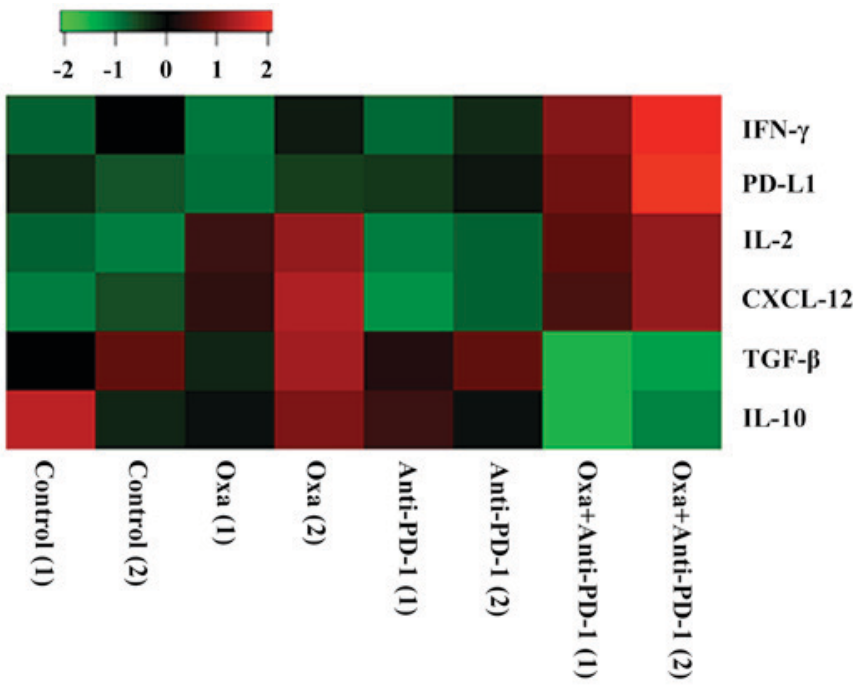

Figure 5. Chemotherapy sensitizes prostate cancer cell to immune checkpoint therapy through changing the expression of immune regulatory cytokines. The cytokines that related to promote immune response and $\mathrm{T}$ cell activation were increased, including IFN- $\gamma$, IL-2 and CXCL-12. The expression of PD-L1 was also increased. However, the expression of TGF- $\beta$ and IL-10 were decreased. Red color indicates higher expression; green color indicates lower expression; and black color indicates average value.

the combination treatment of oxaliplatin and anti-PD-1 $\mathrm{Ab}$ increased the expression of IFN- $\gamma$, PD-L1, IL-2 and CXCL-12; while inhibited the expression of TGF- $\beta$, IL-10. This cytokine network changes is favorable for $\mathrm{T}$ cell activation and antigen presenting. Therefore, it is reasonable to conclude that oxaliplatin sensitizes prostate cancer to immune checkpoint blockade by inducing pro-immuneresponsephenotype.

\section{Discussion}

Immune checkpoints are molecules in the immune system that either boost up a signal, such CD28 and CD137 or turn down a signal, such as PD-1 and CTLA-4 (18-21). Many cancers protect themselves from the immune system by inhibiting the $\mathrm{T}$ cell signal via dampening co-stimulatory signals and enhancing inhibitory signals (7). From 2010, inhibitors of inhibitory immune checkpoints, referred as immune checkpoint blockades, started to be approved for the treatment of multiple cancers $(12,22,23)$. However, a great proportion of solid tumors are resistant to immune checkpoint blockades monotherapy due to low tumor immunogenicity and heavy immunosuppression (7). Recently studies showed that chemotherapies are sensitizers of immune checkpoint blockades in certain types of tumors. Here, we investigated the role of chemotherapy drug oxaliplatin in sensitizing anti-PD-1 Ab in prostate cancer.

Chemotherapy is a common option for ADT insensitive and late stage castration resistant prostate cancer patients (24-26). As a chemotherapy drug, oxaliplatin is used in many cancers, such as colorectal cancer and lung cancer $(27,28)$. In recent years, it's also actively researched in castration resistant prostate cancer patients $(29,30)$. Our data indicated that even cancer cells are resistant to ADT, they can be sensitive to chemotherapy, such as oxaliplatin due to its non-targeted cell death induction roles (31). In our syngeneic animal model of prostate cancer, either oxaliplatin or anti-PD-1 Ab increased overall survival marginally. However, when combined with oxaliplatin, anti-PD-1 Ab showed an obvious prolonged overall survival, suggesting that anti-PD-1 Ab treatment was sensitized by oxaliplatin.

For dissecting the antitumor mechanism of oxaliplatin sensitizing anti-PD-1 Ab, we found that this process involves in modulation of adaptive immunity. In line with the in vitro data that oxaliplatin induced immunogenic phenotype of prostate cancer cells, our animal data confirmed these mechanisms by using oxaliplatin killed tumor cells as tumor vaccine. Additional studies revealed that oxaliplatin treatment regulated $\mathrm{T}$ cell subpopulation in tumor and draining lymphnodes. The ratio of cytotoxic $\mathrm{T}$ cells to Treg cells was increase dramatically meaning an immunogenic tumor microenvironment $(8,10)$. The antitumor functions of tumor specific $\mathrm{T}$ cells rely on positive regulation of cytokines and chemokines. Our data showed that oxaliplatin and anti-PD-1 Ab combination enhance dsecretion of cytokines, such as IFN- $\gamma$, IL-2 and CXCL-12, which are related to promoteantigen presentation, activate immune cells, recruit leukocytes and induce inflammation (32-34). Whereas the decreased cytokines are related to inhibiting antigen presentation, depressing co-stimulatory molecules and inducing Treg cells differentiation (35). As a negative feedback mechanism of anti-PD-1 treatment, PD-L1 expression level was also elevated in combination treatment group. All these data supported the idea that oxaliplatin and anti-PD-1 Ab combination induced prostate cancer regression via systematic activation of adaptive immune response.

In conclusion, as far as we knew, our study showed that oxaliplatin sensitizes anti-PD-1 Ab treatment in prostate cancer for the first time. The chemotherapy drug oxaliplatin stimulated immunogenic potential of prostate cancer, induced systemic antitumor immune response and therefore enhanced anti-PD-1 Ab effects in prostate cancer pre-clinical model. Further clinical studies based on these pre-clinical results are highly wanted.

\section{Acknowledgements}

We thank Basic Medical Research Center of Tianjin Nankai Hospital for her excellent technical assistance and helpful criticism of the manuscript.

\section{References}

1. Porche D: Prostate cancer: Overview of screening, diagnosis and treatment. Adv NPs PAs 2: 18-21; quiz 22, 2011.

2. Bray F, Ferlay J, Laversanne M, Brewster DH, Gombe Mbalawa C, Kohler B, Piñeros M, Steliarova-Foucher E, Swaminathan R, Antoni S, et al: Cancer incidence in five continents: Inclusion criteria, highlights from volume $\mathrm{X}$ and the global status of cancer registration. Int J Cancer 137: 2060-2071, 2015.

3. Grönberg H: Prostate cancer epidemiology. Lancet 361: 859-864, 2003.

4. Jemal A, Murray T, Ward E, Samuels A, Tiwari RC, Ghafoor A, Feuer EJ and Thun MJ: Cancer statistics, 2005. CA Cancer J Clin 55: 10-30, 2005.

5. Hussain S, Haidar A, Bloom RE, Zayouna N, Piper MH and Jafri SM: Bicalutamide-induced hepatotoxicity: A rare adverse effect. Am J Case Rep 15: 266-270, 2014.

6. Sweeney CJ, Chen YH, Carducci M, Liu G, Jarrard DF, Eisenberger M, Wong YN, Hahn N, Kohli M, Cooney MM, et al: Chemohormonal therapy in metastatic hormone-sensitive prostate cancer. N Engl J Med 373: 737-746, 2015. 
7. Postow MA, Callahan MK and Wolchok JD: Immune checkpoint blockade in cancer therapy. J Clin Oncol 33: 1974-1982, 2015.

8. Sato E, Olson SH, Ahn J, Bundy B, Nishikawa H, Qian F, Jungbluth AA, Frosina D, Gnjatic S, Ambrosone C, et al: Intraepithelial CD8+ tumor-infiltrating lymphocytes and a high CD8+/regulatory $\mathrm{T}$ cell ratio are associated with favorable prognosis in ovarian cancer. Proc Natl Acad Sci USA 102 18538-18543, 2005.

9. Naito Y, Saito K, Shiiba K, Ohuchi A, Saigenji K, Nagura H and Ohtani $\mathrm{H}: \mathrm{CD} 8+\mathrm{T}$ cells infiltrated within cancer cell nests as a prognostic factor in human colorectal cancer. Cancer Res 58: 3491-3494, 1998

10. Fu J, Xu D, Liu Z, Shi M, Zhao P, Fu B, Zhang Z, Yang H, Zhang $\mathrm{H}$, Zhou $\mathrm{C}$, et al: Increased regulatory $\mathrm{T}$ cells correlate with CD8 T-cell impairment and poor survival in hepatocellular carcinoma patients. Gastroenterology 132: 2328-2339, 2007.

11. Robert C, Ribas A, Wolchok JD, Hodi FS, Hamid O, Kefford R, Weber JS, Joshua AM, Hwu WJ, Gangadhar TC, et al: Anti-p rogrammed-death-receptor-1 treatment with pembrolizumab in ipilimumab-refractory advanced melanoma: A randomised dose-comparison cohort of a phase 1 trial. Lancet 384: 1109-1117, 2014.

12. Robert C, Schachter J, Long GV, Arance A, Grob JJ, Mortier L, Daud A, Carlino MS, McNeil C, Lotem M, et al: Pembrolizumab versus ipilimumab in advanced melanoma. N Engl J Med 372: 2521-2532, 2015

13. Schadendorf D, Hodi FS, Robert C, Weber JS, Margolin K, Hamid O, Patt D, Chen TT, Berman DM and Wolchok JD: Pooled analysis of long-term survival data from Phase II and Phase III trials of ipilimumab in unresectable or metastatic melanoma J Clin Oncol 33: 1889-1894, 2015.

14. Minn AJ and Wherry EJ: Combination cancer therapies with immune checkpoint blockade: Convergence on interferon signaling. Cell 165: 272-275, 2016.

15. Galsky MD, Noah H, Starodub A, Hauke RJ, Twardowski P, Fleming M, Qi J, Sonpavde G, Patel M, Zhu J, et al: Impact of chemotherapy alone, and chemotherapy plus ipilimumab, on circulating immune cells in patients with metastatic bladder cancer. J Immunother Cancer 3 (Suppl 2): P257, 2015.

16. Zamarin D and Postow MA: Immune checkpoint modulation: Rational design of combination strategies. Pharmacol Ther 150: 23-32, 2015.

17. Zhao X, He Y, Gao J, Fan L, Li Z, Yang G and Chen H: Caveolin-1 expression level in cancer associated fibroblasts predicts outcome in gastric cancer. PLoS One 8: e59102, 2013.

18. Eastwood D, Findlay L, Poole S, Bird C, Wadhwa M, Moore M, Burns C, Thorpe R and Stebbings R: Monoclonal antibody TGN1412 trial failure explained by species differences in CD28 expression on CD4+ effector memory T-cells. Br J Pharmacol 161: 512-526, 2010.

19. Mittler RS, Foell J, McCausland M, Strahotin S, Niu L, Bapat A and Hewes LB: Anti-CD137 antibodies in the treatment of autoimmune disease and cancer. Immunol Res 29: 197-208, 2004.

20. Kolar P, Knieke K, Hegel JK, Quandt D, Burmester GR, Hoff H and Brunner-Weinzierl MC: CTLA-4 (CD152) controls homeostasis and suppressive capacity of regulatory $\mathrm{T}$ cells in mice. Arthritis Rheum 60: 123-132, 2009.
21. Philips GK and Atkins M: Therapeutic uses of anti-PD-1 and anti-PD-L1 antibodies. Int Immunol 27: 39-46, 2015.

22. Robert C, Long GV, Brady B, Dutriaux C, Maio M, Mortier L, Hassel JC, Rutkowski P, McNeil C, Kalinka-Warzocha E, et al: Nivolumab in previously untreated melanoma without BRAF mutation. N Engl J Med 372: 320-330, 2015.

23. Larkin J, Chiarion-Sileni V, Gonzalez R, Grob JJ, Cowey CL, Lao CD, Schadendorf D, Dummer R, Smylie M, Rutkowski P, et al: Combined nivolumab and ipilimumab or monotherapy in untreated melanoma. N Engl J Med 373: 23-34, 2015.

24. Berthold DR, Pond GR, Soban F, de Wit R, Eisenberger M and Tannock IF: Docetaxel plus prednisone or mitoxantrone plus prednisone for advanced prostate cancer: Updated survival in the TAX 327 study. J Clin Oncol 26: 242-245, 2008.

25. Galsky MD and Vogelzang NJ: Docetaxel-based combination therapy for castration-resistant prostate cancer. Ann Oncol 21: 2135-2144, 2010

26. Singh RP and Agarwal R: Prostate cancer chemoprevention by silibinin: Bench to bedside. Mol Carcinog 45: 436-442, 2006

27. Boxberger F, Albrecht H, Konturek PC, Reulbach U, Maennlein G, Meyer T, Hohenberger W, Hahn EG and Wein A: Neoadjuvant treatment with weekly high-dose 5-fluorouracil as a 24 h-infusion, folinic acid and biweekly oxaliplatin in patients with primary resectable liver metastases of colorectal cancer: Long-term results of a phase II trial. Med Sci Monit 16 : CR49-CR55, 2010

28. Zhang K, Qin H, Pan F, Liu E, Liang H and Ruan Z: Nedaplatin or oxaliplatin combined with paclitaxel and docetaxel as first-line treatment for patients with advanced non-small cell lung cancer. Med Sci Monit 20: 2830-2836, 2014

29. Droz JP, Muracciole X, Mottet N, Ould Kaci M, Vannetzel JM, Albin N, Culine S, Rodier JM, Misset JL, Mackenzie S, et al: Phase II study of oxaliplatin versus oxaliplatin combined with infusional 5-fluorouracil in hormone refractory metastatic prostate cancer patients. Ann Oncol 14: 1291-1298, 2003

30. Dorff TB, Tsao-Wei DD, Groshen S, Boswell W, Goldkorn A, Xiong S, Quinn DI and Pinski JK: Efficacy of oxaliplatin plus pemetrexed in chemotherapy pretreated metastatic castration-resistant prostate cancer. Clin Genitourin Cancer 11: 416-422, 2013

31. Shan B, Ma F, Wang M and Xu X: Down-regulating receptor interacting protein kinase 1 (RIP1) promotes oxaliplatin-induced Tca8113 cell apoptosis. Med Sci Monit 21: 3089-3094, 2015.

32. Horwitz DA, Zheng SG, Wang J and Gray JD: Critical role of IL-2 and TGF-beta in generation, function and stabilization of Foxp3+CD4+ Treg. Eur J Immunol 38: 912-915, 2008.

33. Nanki T and Lipsky PE: Stimulation of T-Cell activation by CXCL12/stromal cell derived factor-1 involves a G-protein mediated signaling pathway. Cell Immunol 214: 145-154, 2001.

34. Whitmire JK, Tan JT and Whitton JL: Interferon-gamma acts directly on CD8+ T cells to increase their abundance during virus infection. J Exp Med 201: 1053-1059, 2005.

35. Fu S, Zhang N, Yopp AC, Chen D, Mao M, Chen D, Zhang H, Ding Y and Bromberg JS: TGF-beta induces Foxp3 + T-regulatory cells from CD4+ CD25- precursors. Am J Transplant 4: 1614-1627, 2004. 